\title{
Development of a polyvinylidene difluoride membrane for nanofiltration
}

\author{
M. Mertens, T. Van Dyck, C. Van Goethem, A.Y. Gebreyohannes, Ivo F.J. Vankelecom* \\ Centre for Surface Chemistry and Catalysis, Faculty of Bioscience Engineering, KU Leuven, Celestijnenlaan 200F, Box 2461, 3001 Leuven, Belgium
}

\section{A R T I C L E I N F O}

\section{Keywords:}

Polyvinylidene difluoride

Nanofiltration

Flat sheet

Phase inversion

\begin{abstract}
A B S T R A C T
Integrally skinned asymmetric nanofiltration (NF) membranes are widely used for treating a variety of aqueous and solvent streams. Polyvinylidene difluoride (PVDF), is an excellent film forming polymer with outstanding chemical, thermal and mechanical stability. However, additive-free PVDF membranes with pores small enough to apply them in NF do not currently exist. By accurately tuning the phase inversion parameters (i.e. polymer concentration, co-solvent concentration and evaporation time), a membrane was obtained that retains for $80 \%$ a $327 \mathrm{Da}$ solute from an aqueous solution at a permeance of $1.8 \mathrm{LMH} / \mathrm{bar}$ when operated at $10 \mathrm{bar}$. The membranes were characterised by XRD and SEM, while the membrane formation process was characterised using viscosity measurements and cloud point determinations.
\end{abstract}

\section{Introduction}

Polymeric nanofiltration (NF) membranes can be prepared either as thin film composite or integrally skinned asymmetric membranes. For both types of membranes, a wide range of polymers have been thoroughly studied. Compared to inorganic NF membranes which are usually more stable, polymeric NF membranes have the advantages of being relatively cheap and easier to produce and upscale. Disadvantages are their limited thermal and chemical stability which results in a shorter lifetime and diminishing performances over time $[1,2]$.

Hydrophobic polymers, like polyvinylidene difluoride (PVDF), are frequently used for membrane preparation as these are intrinsically more chemically stable. PVDF is widely used in membrane distillation, membrane contactors, wastewater treatment, biomedical and bio-separation applications covering aqueous microfiltration (MF), ultrafiltration (UF) and nanofiltration (NF), and gas separation [3]. Although PVDF-based UF and MF flat sheet membranes are commercially available, there is a clear knowledge gap on the formation of PVDF membranes with performances in the NF-range. Literature does report PVDF membranes with NF separation capabilities, but these were always realised through modifications of PVDF, e.g. through blending or post treatment, to obtain NF performances [4-7]. PVDF membranes, even though being more sensitive to fouling due to their hydrophobic character, would be of high interest for purifying streams which are rich in foulants, as PVDF is known to resist conventional membrane cleaning conditions very well in food, industrial and wastewater applications [1,8-12].
To obtain a castable polymer solution, PVDF is dissolved in aprotic organic solvents, usually N-methylpyrrolidone (NMP), dimethylsulfoxide (DMSO), N,N-dimethylformamide (DMF) or N,N-dimethylacetamide (DMAc) [3,13-15]. In order to densify the top layer further into an integrally skinned asymmetric membrane, a co-solvent, often volatile, is added to the polymer solution $[13,16,17]$. Co-solvents can typically be tetrahydrofuran (THF), acetone, ethanol or dioxane. Partial evaporation of this volatile co-solvent before phase inversion in a coagulation bath is the key to get a high polymer concentration near the membrane surface $[12,13,18-21]$. Nonetheless, there are still incongruities in literature as to what effect the addition and evaporation of a co-solvent and the evaporation time have. Contrary to what was claimed for years, studies on cellulose acetate (CA) and polyimide (PI) showed that shortening the evaporation step significantly increased the perm-selectivity of the membranes $[13,22,23]$. Even more, it has become arguable whether an evaporation step is even necessary at all, since certain mixtures of solvent and co-solvent in some cases yield high rejections [13,24-26].

The aim of this work is to develop a tight PVDF membrane for aqueous NF. The phase inversion parameters that are tuned are the polymer concentration, the optimal solvent:co-solvent ratio (NMP:THF) and the evaporation time. The membrane performance was tested using an aqueous Methyl Orange (MO) solution, followed by benchmarking with commercially available NF-membranes.

\footnotetext{
* Corresponding author.

E-mail address: ivo.vankelecom@kuleuven.be (I.F.J. Vankelecom).
} 


\section{Experimental}

\subsection{Chemicals}

Polyvinylidene difluoride (PVDF, $\mathrm{MW}_{\mathrm{avg}} \sim 543,000 \mathrm{Da}$ ) powder and tetrahydrofuran (THF) were acquired from Sigma-Aldrich (Belgium), and N-methyl-2-pyrrolidone (NMP, 99\%) from Acros. All water was removed from both solvents using zeolite $3 \mathrm{~A}$ beads and drying the polymer at $100{ }^{\circ} \mathrm{C}$ before use. Methyl Orange (MO, MW $327 \mathrm{Da}$ ) was purchased from Fluka.

\subsection{Membrane preparation}

A series of PVDF membranes were prepared with varying PVDF concentrations in NMP. Next, three series of PVDF/NMP/THF membranes were made with a fixed PVDF concentration (20 wt\%), varying NMP:THF-ratios and different evaporation time.

All membranes were cast on a dry glass plate using a Braive instruments automatic film applicator at a casting speed of $2.25 \mathrm{~cm} / \mathrm{s}$ and a casting thickness of $250 \mu \mathrm{m}$, after which the cast films were immediately, or after evaporation in the case of co-solvent addition, immersed in demineralised water $\left(20^{\circ} \mathrm{C}\right)$ to induce phase inversion $[16,27,28]$. During this process, temperature, relative humidity and evaporation time (incl. pouring time, casting and evaporation) were controlled as they have a profound effect on the membrane formation and performance. The formed films were stored in demineralised water $\left(20^{\circ} \mathrm{C}\right)$ until further use. Details can be found in Table 1.

\subsection{Filtration experiments}

Filtrations were performed in a dead-end high-throughput filtration cell, capable of testing 16 membranes simultaneously with an active area of $0.00177 \mathrm{~m}^{2}$ per membrane. An aqueous solution of $35 \mu \mathrm{M} \mathrm{MO}$ was used as feed and was stirred at $500 \mathrm{rpm}$ to minimize concentration polarization. Prior to filtration, 3 coupons from one membrane sheet for each commercial and lab-made membrane were soaked $(2 \mathrm{~h})$ in technical ethanol (Disinfectol, Chem-Lab, Belgium). Next, the membranes were stabilized through filtration at $10 \mathrm{bar}$ for $20 \mathrm{~h}$, after which permeate was collected for analysis. Permeances were determined gravimetrically using Eq. (1) whereas Eq. (2) was used to determine the dye retentions spectrophotometrically using a Shimadzu UV-1800 UV-VIS spectrophotometer at $507 \mathrm{~nm}$ against water.

Permeance $=\frac{V}{\text { A. t. } \Delta P}$
Retention $=\frac{C_{f}-C_{p}}{C_{f}} \cdot 100$

where $\mathrm{V}$ is the permeate volume [L]; A the active membrane surface $\left[\mathrm{m}^{2}\right] ; \mathrm{t}$ the filtration duration $[\mathrm{h}] ; \Delta \mathrm{P}$ the pressure over the membrane [bar]; $C_{f}$ is the feed dye concentration and $C_{p}$ the permeate dye concentration $[\mu \mathrm{M}]$.

Table 1

Membrane preparation parameters and values.

\begin{tabular}{lll}
\hline Parameter & Values & Units \\
\hline Polymer concentration & $17-24$ & $\mathrm{wt} \%$ \\
NMP:THF ratio (w/w) & $100: 0-60: 40$ & - \\
Stirring temperature & 25 & ${ }^{\circ} \mathrm{C}$ \\
Degassing time & 1 & $\mathrm{day}$ \\
Casting speed & 2.25 & $\mathrm{~cm} / \mathrm{s}$ \\
Casting thickness & 250 & $\mu \mathrm{m}$ \\
Evaporation time & $5-60$ & $\mathrm{~s}$ \\
Time in coagulation bath & 1 & $\mathrm{~h}$ \\
Temperature & 20 & ${ }^{\circ} \mathrm{C}$ \\
Relative humidity & 40 & $\%$ \\
\hline
\end{tabular}

\subsection{Membrane characterisation}

The structure of membrane cross-sections was characterised by scanning electron microscopy (SEM) using a JEOL JSM-6010LV Scanning Electron Microscope (JEOL, Tokyo, Japan). The liquid nitrogen fractured samples were coated with an $\mathrm{Au} / \mathrm{Pd}$ coating via an auto fine coater JEOL JFC-1300 (JEOL, Tokyo, Japan) to minimize sample charging.

Crystal structure of the membrane sheets were examined through Xray diffraction (XRD) on a STOE stadi P diffractometer in transmission mode using CuK $\alpha$ radiation $(\lambda=1.5418 \AA)$. For each membrane XRD data was collected for $1 \mathrm{~h}$ in order to improve the signal to noise ratio.

Cloudpoints were visually determined while assessing the stability of the casting solution by titrating with non-solvent. For the sake of viscosity, a polymer concentration of $15 \mathrm{wt} \%$ was used with NMP:THF ratios from 100:0 till 60:40.

The rheological measurements were performed on a stress-controlled rheometer (Anton Paar MCR501) with cone-plate geometry and evaporation blocker. A cone-plate geometry of $25 \mathrm{~mm}$ and $2^{\circ}$ cone angle was used for the highly viscous samples (viscosities above $10 \mathrm{~Pa} \mathrm{~s}$ ). The sample temperature was controlled at $20^{\circ} \mathrm{C}$ with a Peltier element with accuracy around $0.1{ }^{\circ} \mathrm{C}$. Viscosity as a function of shear rate was probed in steady shear flow (from 0.01 to 101 /s with 5 datapoints per decade). The RheoPlus software (Anton Paar GmbH, Austria) was used for data acquisition and analysis. A Newtonian plateau was observed for all liquids. Hence, the zero-shear viscosity was calculated as the average taken over the first five datapoints (shear rates between 0.01 and 0.11 / s).

\subsection{Commercial membranes}

To benchmark the lab-made membranes, commercial membranes were purchased from Sterlitech. The selection includes different polymers and molecular weight cut-offs (MWCO) (Table S1). Before filtration, each membrane was wet in technical ethanol for $2 \mathrm{~h}$ to fully activate all pores.

\section{Results and discussion}

The three main phase inversion parameters, which were studied to obtain a denser membrane with NF properties are: the polymer concentration, addition of a volatile co-solvent and the evaporation time for the cast film before immersion in the non-solvent bath. Among the various commercial membranes used for benchmarking, NADIR NP030 represents an integrally asymmetric membrane. Hence, the water permeance and MO retention of NADIR NP030 was set as target for the present membrane.

\subsection{Polymer concentration}

As expected, increasing the polymer concentration from 17 to $24 \mathrm{wt}$ $\%$ increased the membrane retention while the permeance dropped (Fig. 1). As concentration increased, the system became considerably more viscous (ranging from 14.3 Pa s to $145.5 \mathrm{~Pa} \mathrm{~s}$; Table 2), and finally even resulted in heterogeneous solutions which were difficult to cast in a reproducible manner for the highest concentrations. Therefore, based on the visual condition of the casting solution (i.e. insufficient dissolution) and supported by viscosity data, a polymer concentration of $20 \mathrm{wt} \%$ was chosen for further optimization.

\subsection{Effect of volatile co-solvent}

Varying the polymer concentration was insufficient to reach the set NF-targets. Therefore, the system was further tuned by adding a volatile co-solvent (i.e. THF). This co-solvent evaporates during an evaporation step $(60 \mathrm{~s})$ prior to immersion in the non-solvent. The relative polymer 


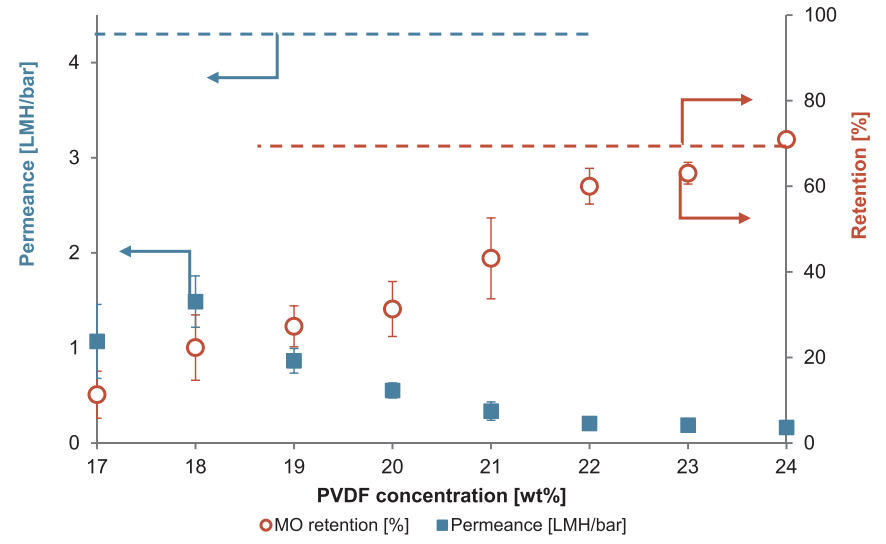

Fig. 1. Filtration performance of the PVDF series with varying polymer concentration (17-24 wt\%) from casting solutions without THF. The red and blue dashed lines represent the retention and permeance targets respectively. (For interpretation of the references to color in this figure legend, the reader is referred to the web version of this article.).

Table 2

Viscosity (Pas) at a shear rate of $0.011 / \mathrm{s}$ of the PVDF series with varying polymer concentration (17-24 wt\%) in the casting solution without THF.

\begin{tabular}{llllll}
\hline Polymer concentration (wt\%) & 17 & 19 & 20 & 21 & 24 \\
Viscosity (Pa s) & 14,3 & 24,9 & 29,7 & 39,0 & 145,5
\end{tabular}

concentration at the membrane surface increases during this evaporation step, thereby slowing down the mass transfer and thus delaying the solvent/non-solvent exchange rate, resulting in a further densification of the top layer $[12,29,30]$.

As PVDF is a semi-crystalline polymer with $4(\alpha-, \beta-, \gamma$ and $\delta$-phase) possible crystallographic phases, XRD was done on the membranes (Fig. 2). The $\alpha$-phase is kinetically favored while the $\beta$-phase is thermodynamically the most stable one [31].

A modest shift in peak maximum was noticed in the diffraction pattern (Fig. 2) from a $2 \theta$-value of 19.9 towards 20.3 with lower THF concentration in the solvent mixture. This indicates a change in crystallographic structure upon change in THF content [32-34]: with less THF present, more $\beta$-phase is thus formed. This confirms the anticipated trend: with a weak solvent (i.e. THF) replacing a good solvent (i.e. NMP), the solubility and mobility of the polymer is reduced, thereby preventing polymer chains from rearranging towards the thermodynamically stable $\beta$-phase [35]. To validate the weak solvent character of THF, cloudpoints were determined. A similar system with a lower polymer concentration was used for practical reasons. These

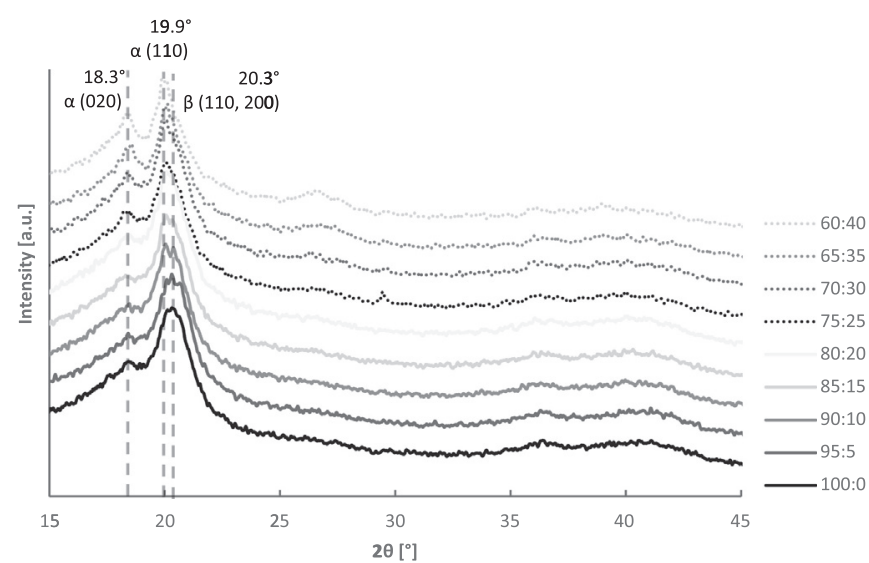

Fig. 2. Diffraction pattern of the $20 \mathrm{wt} \%$ PVDF membranes with different NMP:THF ratio's.

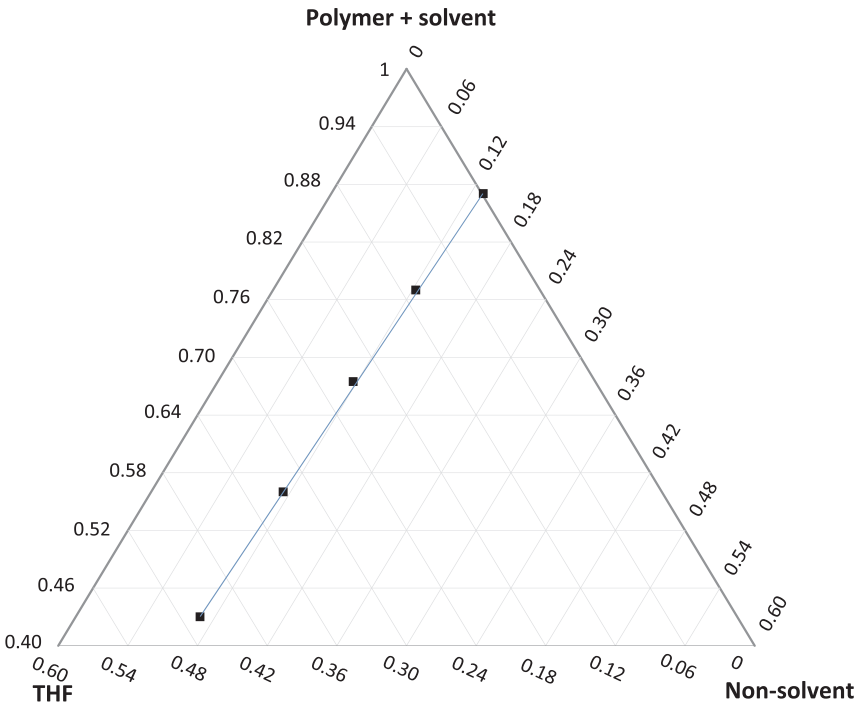

Fig. 3. Cloudpoint data of polymer solutions ( $15 \mathrm{wt} \%)$ containing increasing THF concentration.

cloudpoint data in Fig. 3 confirmed the destabilising effect of THF on the casting solution.

When a polymer solution is less stable (i.e. closer to the binodal), a smaller amount of non-solvent is needed to make it demix, leading to instantaneous demixing, resulting in a more porous structure. This process is enhanced by the evaporation, which becomes more significant with increasing THF concentration, in accordance with other findings $[31,36]$.

As clearly seen from the SEM images (Fig. 4), adding THF results in a microscopically denser membrane with a sponge-like structure (i.e. delayed demixing), as also found elsewhere [3,37-40]. These observations contradict with our findings above and what generally would be expected from adding THF. However, different phenomena (e.g. kinetics, thermodynamics etc.) play a role in these systems and it is often hard to predict which phenomena will get the upper hand in determining the membrane performance.

Fig. 5 shows the filtration performance upon adding co-solvent and evaporation step. A $71 \%$ retention of MO, which is close to the set target retention of 70\% was achieved even at the lowest amount of cosolvent added. This is a significant improvement compared to the retention obtained for the reference, i.e. THF-free, PVDF membrane (31\%). However, addition of THF brought a negative effect on the permeance. As the membrane became tighter, the permeance dropped. Consequently, the performance data favour the SEM observations (i.e. more THF results in a denser membrane).

\subsection{Effect of evaporation time}

As addition of THF was not sufficient to reach the set target NF performance, the membrane was further tuned with varying the evaporation duration. To minimize the negative effects of THF addition on the membrane permeance, the 95:5-membrane was selected. Moreover, the membrane cast from the solution with a 95:5 NMP:THF ratio already gave a retention close to the set target value. The evaporation time was shortened from $60 \mathrm{~s}$ to $30 \mathrm{~s}$ and $5 \mathrm{~s}$, which is the absolute minimum time required for transferring in practice at lab-scale the cast film into the coagulation bath.

By shortening the evaporation time (Fig. 6), both permeance and retention were improved by $+385 \%$ and $+15 \%$ respectively, in agreement with other findings $[13,24,26]$. Using SEM (Fig. 7), a more porous sublayer with larger macrovoids was observed in line with literature $[3,37,38]$. According to others, the slightly improved membrane retention by shortening the evaporation step might not be 


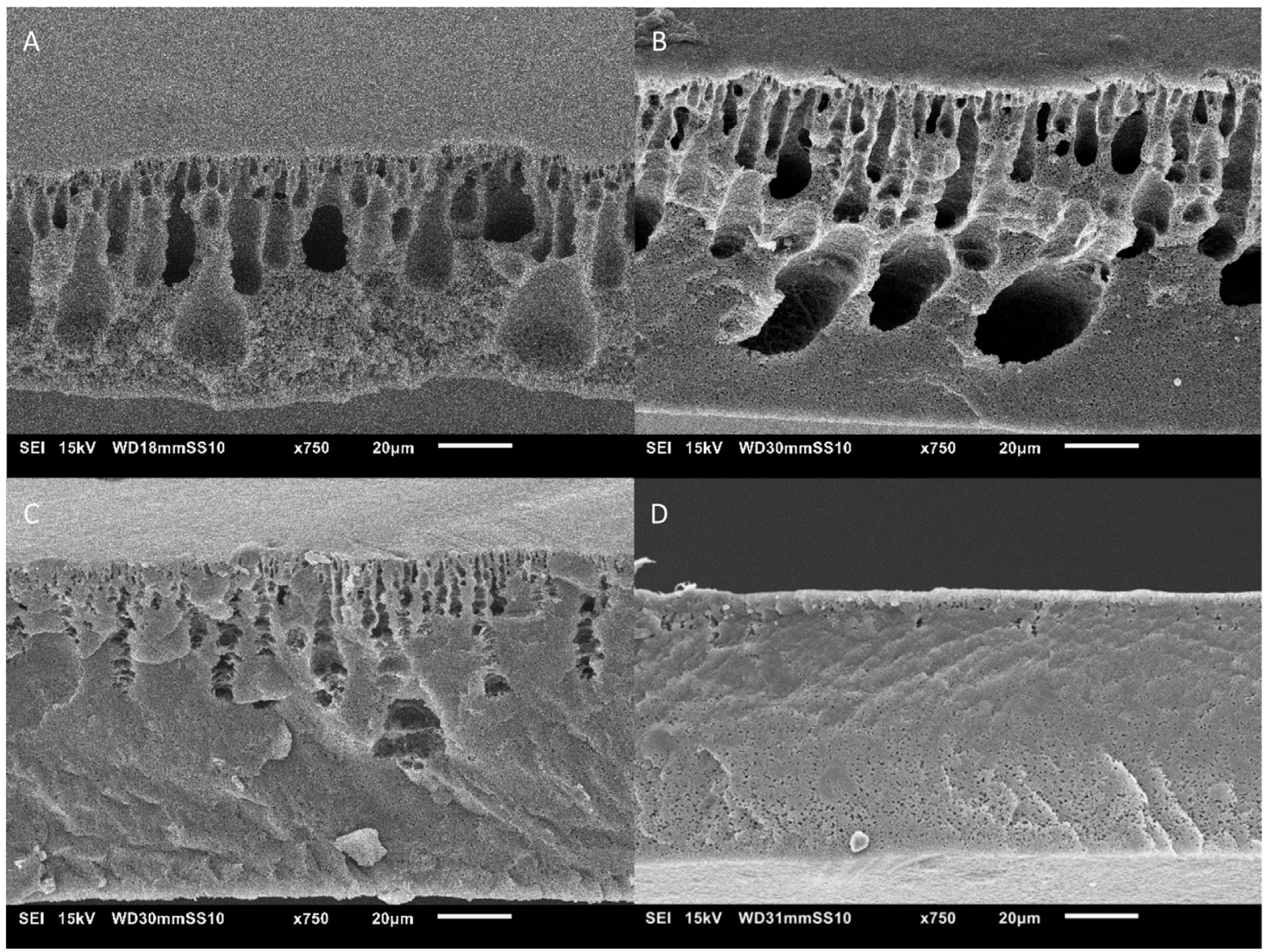

Fig. 4. SEM images of the $20 \mathrm{wt} \%$ PVDF membranes with $60 \mathrm{~s}$ evaporation step and different NMP:THF ratios: $\mathrm{A}=0 \% \mathrm{THF}(100: 0) ; \mathrm{B}=5 \%$ THF $(95: 5)$; $\mathrm{C}=15 \%$ THF (85:15); D = 40\% THF (60:40).

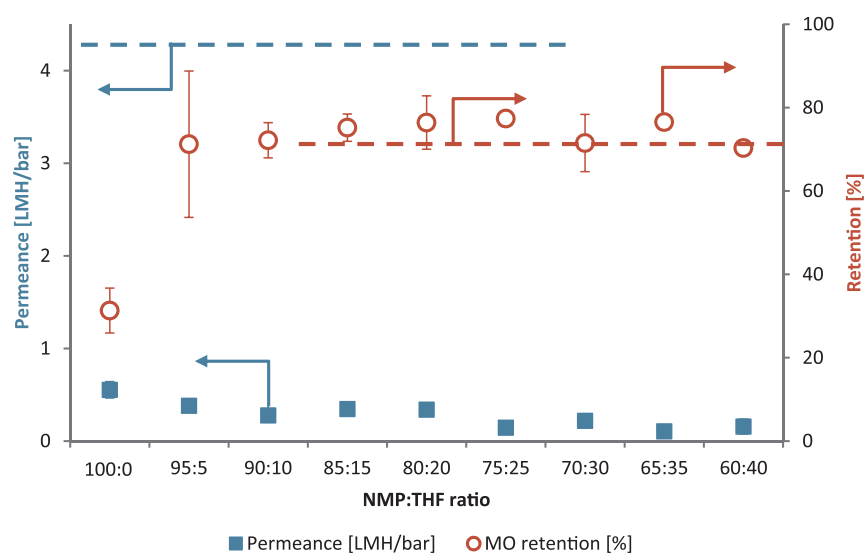

Fig. 5. Filtration performance of $20 \mathrm{wt} \%$ PVDF membranes with different NMP:THF ratios and $60 \mathrm{~s}$ evaporation. The red and blue lines represent the retention and permeance targets respectively. (For interpretation of the references to color in this figure legend, the reader is referred to the web version of this article.).

anticipated; even a drop can be expected $[13,16,41]$. It is assumed that the slight increase originates from the water that is condensing from the atmosphere on the cast polymer solution which is intensified when more THF evaporates. This evaporation extracts heat from the surface of the cast film which thus locally cools down. This increased condensation of water onto the membrane surface destabilizes the system, resulting in a slightly more porous top layer at higher evaporation times $[42,43]$.

After screening these three main parameters of the phase inversion process, the best PVDF membrane (prepared with the lowest THF

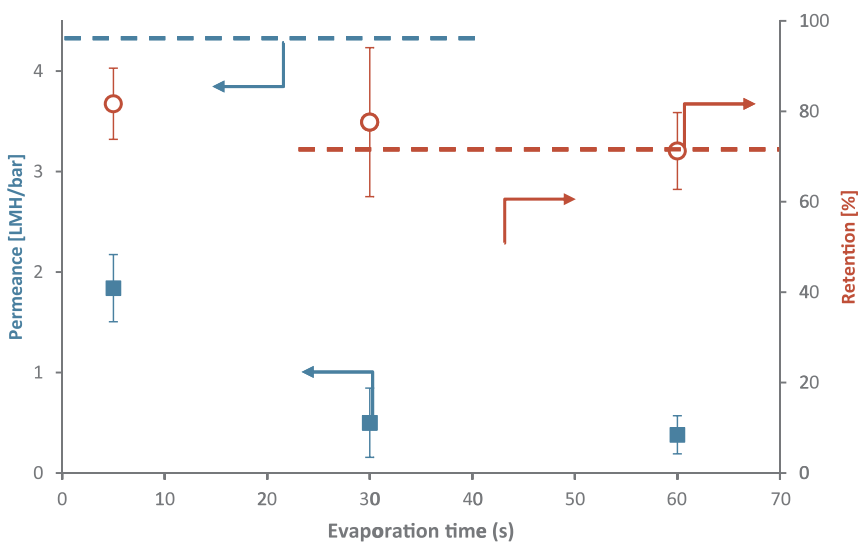

Fig. 6. Filtration performance of $20 \mathrm{wt} \%$ PVDF membranes with 5\% THF (95:5) at different evaporation times (5-30-60 s). The red and blue lines represent the retention and permeance targets respectively. (For interpretation of the references to color in this figure legend, the reader is referred to the web version of this article.).

concentration and shortest evaporation time), has a permeance of 1,8 $\mathrm{LMH} /$ bar and a MO $(327 \mathrm{Da})$ retention of $81 \%$. To benchmark this membrane, a series of commercially available membranes were also filtered with MO (Fig. 8). Typical commercial NF membranes are made from PA or PES. Unlike PVDF, PA membranes are known to be less stable towards aggressive cleaning procedures and chlorine based chemicals. Therefore, two more stable PES-based membranes were included in the test.

Retention-wise, the PVDF membrane outperforms the PES (i.e. NADIR) NF-membranes, from which the NP030 membranes was the set 


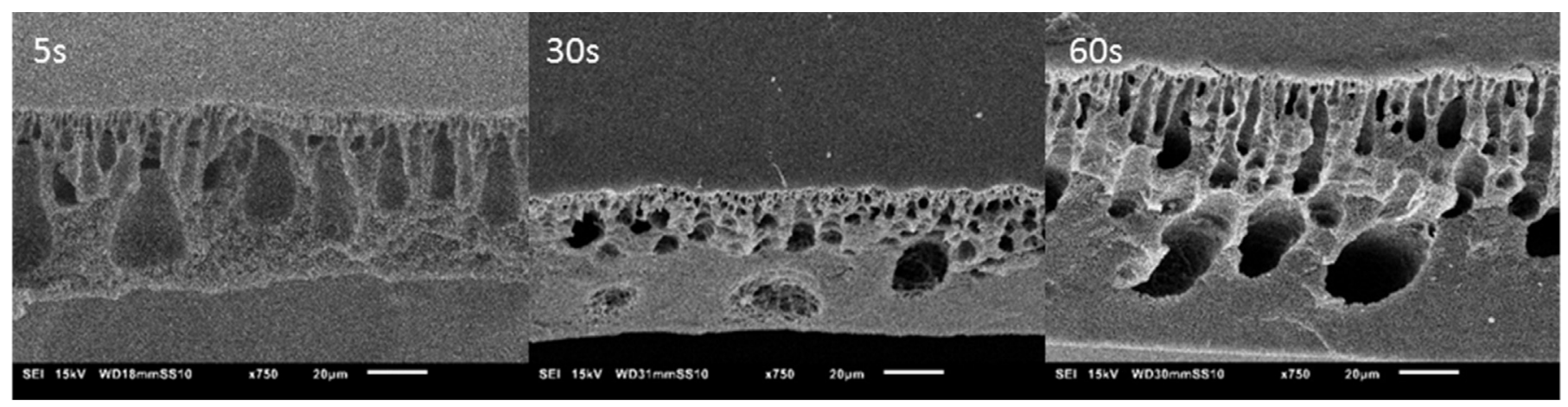

Fig. 7. SEM images of $20 \mathrm{wt} \%$ PVDF membranes with 5\% THF (95:5) at different evaporation times (5-30-60 s).

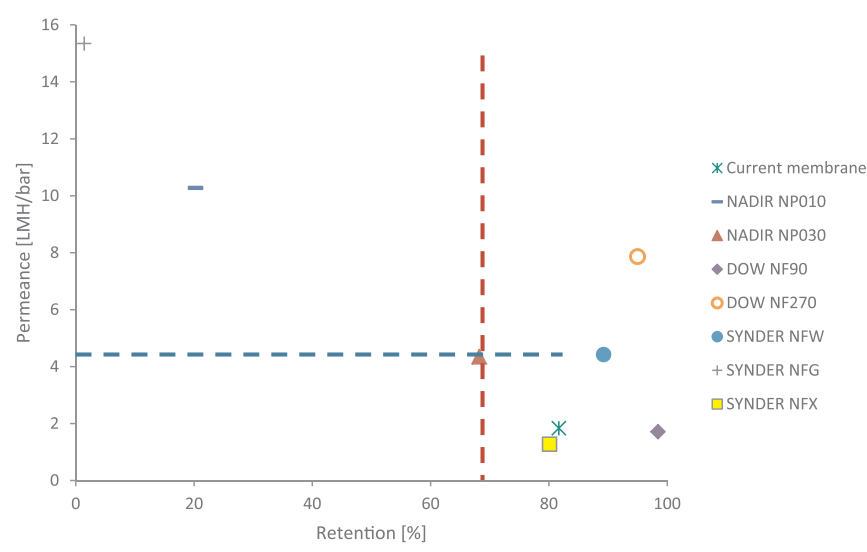

Fig. 8. MO-retention and permeance of commercial and current PVDF (95:5 solvent:co-solvent with $5 \mathrm{~s}$ evaporation time) membranes with the retention (red line) and permeance (blue line) targets. (For interpretation of the references to color in this figure legend, the reader is referred to the web version of this article.).

target. However, considering the MWCO of these membranes (Table S1), it seems logical that the commercial PES membranes are unable to retain the $327 \mathrm{Da}$ dye. Similar conclusion can also be made for the SYNDER NFG commercial membrane.

Permeance-wise, the performance of the present membrane were similar to the DOW NF90 and SYNDER NFX commercial membranes. Although NF90 has a higher retention for equal permeance, it is known to be less stable to chlorine $[44,45]$.

Cellulose acetate (CA) membranes were excluded from the benchmarking as they are sensitive towards microbiological fouling, tend to compact structurally at higher pressures and have a limited operational $\mathrm{pH}$ range $[46,47]$.

\section{Conclusion}

Integrally skinned PVDF-based NF membranes were obtained by tuning three phase inversion parameters (polymer concentration, cosolvent concentration and evaporation time). The optimum membrane has a low co-solvent concentration (i.e. 5\% THF) and an as short as possible evaporation time. Addition of THF to the casting solution densified the membrane, i.e. pointed in the direction of delayed demixing during coagulation, as reflected in separation performance and SEM-images of membrane cross-sections. However, this was not in line with XRD (appearance of more $\alpha$-phase) and cloudpoint determination (less stable casting solutions). The resulting PVDF-membrane is believed to have a large potential in membrane separations and is considered to be competitive with today's NF membranes when a very stable membrane material is required for operation or cleaning under harsh conditions.

\section{Acknowledgments}

The authors would like to thank Anja Vananroye (Dep. of Chemical Engineering (Soft Matter, Rheology and Technology Section), KU Leuven) for measuring and analysing the viscosity data. This work was supported by the Belgian Federal Government (IAP FS2), KU Leuven (C16/17/005 and IOF-KP 13/004) and NWO (SBO-Nanomexico). C.V.G acknowledges the Flemish Agency for Innovation through Science and Technology (IWT) for a Ph.D. scholarship.

\section{Appendix A. Supporting information}

Supplementary data associated with this article can be found in the online version at http://dx.doi.org/10.1016/j.memsci.2018.04.020.

\section{References}

[1] P. Marchetti, M.F.J. Solomon, G. Szekely, A.G. Livingston, Molecular separation with organic solvent nanofiltration: a critical review, Chem. Rev. 114 (2014) 10735-10806, http://dx.doi.org/10.1021/cr500006j.

[2] I.F.J. Vankelecom, K. De Smet, L.E.M. Gevers, P.A. Jacobs, Nanofiltration membrane materials and preparation, in: A.I. Schäfer, A.G. Fane, I.D. Waite (Eds.), Nanofiltration Principles and Application, 2006, pp. 33-66.

[3] F. Liu, N.A. Hashim, Y. Liu, M.R.M. Abed, K. Li, Progress in the production and modification of PVDF membranes, J. Membr. Sci. 375 (2011) 1-27, http://dx.doi. org/10.1016/j.memsci.2011.03.014.

[4] G. Zeng, Z. Ye, Y. He, X. Yang, J. Ma, H. Shi, Z. Feng, Application of dopaminemodified halloysite nanotubes/PVDF blend membranes for direct dyes removal from wastewater, Chem. Eng. J. 323 (2017) 572-583, http://dx.doi.org/10.1016/j. cej.2017.04.131.

[5] C. Sun, X. Feng, Enhancing the performance of PVDF membranes by hydrophilic surface modification via amine treatment, Sep. Purif. Technol. 185 (2017) 94-102, http://dx.doi.org/10.1016/j.seppur.2017.05.022.

[6] G. Zeng, Y. He, Y. Zhan, L. Zhang, Y. Pan, C. Zhang, Z. Yu, Novel polyvinylidene fluoride nanofiltration membrane blended with functionalized halloysite nanotubes for dye and heavy metal ions removal, J. Hazard. Mater. 317 (2016) 60-72, http:// dx.doi.org/10.1016/j.jhazmat.2016.05.049.

[7] N. Nikooe, E. Saljoughi, Preparation and characterization of novel PVDF nanofiltration membranes with hydrophilic property for filtration of dye aqueous solution, Appl. Surf. Sci. 413 (2017) 41-49, http://dx.doi.org/10.1016/j.apsusc.2017.04. 029.

[8] M.S.M. Sueb, J. Zdarta, T. Jesionowski, G. Jonsson, A.S. Meyer, H. Jørgensen, M. Pinelo, High-performance removal of acids and furans from wheat straw pretreatment liquid by diananofiltration, Sep. Sci. Technol. 52 (2017) 1901-1912, http://dx.doi.org/10.1080/01496395.2017.1302951.

[9] G. Kaykioglu, R. Ata, G.Y. Tore, A.O. Agirgan, Evaluation of effects of textile wastewater on the quality of cotton fabric dye, Membr. Water Treat. 8 (2017) 1-18, http://dx.doi.org/10.12989/mwt.2017.8.1.001.

[10] A. Córdova, C. Astudillo, L. Santibañez, A. Cassano, R. Ruby-Figueroa, A. Illanes, Purification of galacto-oligosaccharides (GOS) by three-stage serial nanofiltration units under critical transmembrane pressure conditions, Chem. Eng. Res. Des. 117 (2017) 488-499, http://dx.doi.org/10.1016/j.cherd.2016.11.006.

[11] I. Kowalska, A. Klimonda, Application of nanofiltration membranes for removal of surfactants from water solutions, 44, 2017.

[12] P. Vandezande, L.E.M. Gevers, I.F.J. Vankelecom, Solvent resistant nanofiltration: separating on a molecular level, Chem. Soc. Rev. 37 (2008) 365-405, http://dx.doi. org $/ 10.1039 / \mathrm{b} 610848 \mathrm{~m}$.

[13] I. Soroko, M. Makowski, F. Spill, A. Livingston, The effect of membrane formation parameters on performance of polyimide membranes for organic solvent nanofiltration (OSN). Part B: analysis of evaporation step and the role of a co-solvent, J. Membr. Sci. 381 (2011) 163-171, http://dx.doi.org/10.1016/j.memsci.2011.07. 
028.

[14] A. Bottino, G. Camera-Roda, G. Capannelli, S. Munari, The formation of microporous polyvinylidene difluoride membranes by phase separation, J. Membr. Sci. 57 (1991) 1-20, http://dx.doi.org/10.1016/S0376-7388(00)81159-X.

[15] S. Munari, A. Bottino, G. Capannelli, Casting and performance of polyvinylidene fluoride based membranes, J. Membr. Sci. 16 (1983) 181-193, http://dx.doi.org/ 10.1016/S0376-7388(00)81309-5.

[16] A.K. Hołda, B. Aernouts, W. Saeys, I.F.J. Vankelecom, Study of polymer concentration and evaporation time as phase inversion parameters for polysulfonebased SRNF membranes, J. Membr. Sci. 442 (2013) 196-205, http://dx.doi.org/10. 1016/j.memsci.2013.04.017

[17] P. Vandezande, L.E.M. Gevers, I.F.J. Vankelecom, Solvent resistant nanofiltration separating on a molecular level, Chem. Soc. Rev. 37 (2008) 365-405, http://dx.doi. org/10.1039/B610848M.

[18] J. da Silva Burgal, L. Peeva, P. Marchetti, A. Livingston, Controlling molecular weight cut-off of PEEK nanofiltration membranes using a drying method, J. Membr. Sci. 493 (2015) 524-538, http://dx.doi.org/10.1016/j.memsci.2015.07.012.

[19] Y.H. See-Toh, M. Silva, A. Livingston, Controlling molecular weight cut-off curves for highly solvent stable organic solvent nanofiltration (OSN) membranes, J. Membr. Sci. 324 (2008) 220-232, http://dx.doi.org/10.1016/j.memsci.2008.07. 023.

[20] L.S. White, Polyimide membranes for recovery of aromatic solvents under hyperfiltration conditions, 6,180,008 B1, 2000 .

[21] A. Asadi Tashvigh, L. Luo, T.S. Chung, M. Weber, C. Maletzko, A novel ionically cross-linked sulfonated polyphenylsulfone (sPPSU) membrane for organic solven nanofiltration (OSN), J. Membr. Sci. 545 (2018) 221-228, http://dx.doi.org/10. 1016/j.memsci.2017.09.076.

[22] A.G. Livingston, Y.S. Bhole, Asymmetric membranes for use in nanofiltration, WO/ 125367, 2013.

[23] H. Strathmann, K. Kock, P. Amar, R. Baker, The formation mechanism of asymmetric membranes, Desalination 16 (1975).

[24] K.K. Sirkar, N.K. Agarwal, G.P. Rangaiah, The effect of short air exposure periods on performance of cellulose-acetate membranes from casting solutions with high cellulose-acetate content, Appl. Polym. Sci. 22 (1978) 119-1944, http://dx.doi.org/ 10.1002/app.1978.070220714.

[25] H. Strathmann, K. Kock, P. Amar, R.W. Baker, The formation mechanism of asymmetric membranes, Desalination 16 (1975) 179-203, http://dx.doi.org/10. 1016/S0011-9164(00)82092-5.

[26] M.N. Sarbolouki, Preparation of skinned membranes without evaporation step, Polym. Sci. Part C Polym. Lett. 11 (1973) 753-754, http://dx.doi.org/10.1002/pol. 1973.130111204.

[27] A.K. Holda, I.F.J. Vankelecom, Integrally skinned PSf-based SRNF-membranes prepared via phase inversion-Part A: influence of high molecular weight additives, J. Membr. Sci. 450 (2014) 512-521, http://dx.doi.org/10.1016/j.memsci.2013.08. 050.

[28] A.K. Holda, I.F.J. Vankelecom, Integrally skinned PSf-based SRNF-membranes prepared via phase inversion-Part B: influence of low molecular weight additives, J. Membr. Sci. 450 (2014) 499-511, http://dx.doi.org/10.1016/j.memsci.2013.08. 051.

[29] M. Mulder, Preparation of synthetic membranes, in: Basic Princ. Membr. Technol., 2nd ed., Kluwer Academic Publishers, Dordrecht: 2004: pp. 71-156.

[30] I.F.J. Vankelecom, K. De Smet, L.E.M. Gevers, P.A. Jacobs, Nanofiltration membrane materials and preparation, in: A.I. Schäfer, A.G. Fane, T.D. White (Eds.), Nanofiltration Principles and Applications, Elsevier, Oxford, 2005, pp. 33-65.

[31] R. Gregorio, D.S. Borges, Effect of crystallization rate on the formation of the polymorphs of solution cast poly(vinylidene fluoride), Polymer (Guildf.) 49 (2008)
4009-4016, http://dx.doi.org/10.1016/j.polymer.2008.07.010.

[32] M.G. Buonomenna, P. Macchi, M. Davoli, E. Drioli, Poly(vinylidene fluoride) membranes by phase inversion: the role the casting and coagulation conditions play in their morphology, crystalline structure and properties, Eur. Polym. J. 43 (2007) 1557-1572, http://dx.doi.org/10.1016/j.eurpolymj.2006.12.033.

[33] M.M. Tao, F. Liu, B.R. Ma, L.X. Xue, Effect of solvent power on PVDF membrane polymorphism during phase inversion, Desalination 316 (2013) 137-145, http:// dx.doi.org/10.1016/j.desal.2013.02.005.

[34] J. Yang, X.L. Wang, Y. Tian, Y. Lin, F. Tian, Morphologies and crystalline forms of polyvinylidene fluoride membranes prepared in different diluents by thermally induced phase separation, J. Polym. Sci. Part B Polym. Phys. 48 (2010) 2468-2475 http://dx.doi.org/10.1002/polb.22145.

[35] A. Bottino, G. Capannelli, S. Munari, A. Turturro, Solubility parameters of poly (vinylidene fluoride), J. Polym. Sci. Part B-Polym. Phys. 26 (1988) 758-794, http:// dx.doi.org/10.1002/polb.1988.090260405.

[36] D.L. Chinaglia, J. Rinaldo Gregorio, J.C. Stefanello, R.A.P. Altafim, W. Wirges, F. Wang, R. Gerhard, Influence of the solvent evaporation rate on the crystalline phases of solution-cast poly(vinylidene fluoride) films, J. Appl. Polym. Sci. 116 (2010) 785-791, http://dx.doi.org/10.1002/app.

[37] M. Khayet, C. Cojocaru, M. García-Payo, Experimental design and optimization of asymmetric flat-sheet membranes prepared for direct contact membrane distillation, J. Membr. Sci. 351 (2010) 234-245, http://dx.doi.org/10.1016/j.memsci. 2010.01.057.

[38] J. Wang, Y. Zhang, Y. Xu, B. Zhu, H. Xu, Fabrication of hydrophilic and sponge-like $\mathrm{PVDF} /$ brush-like copolymer blend membranes using triethylphosphate as solvent, Chin. J. Polym. Sci. 32 (2014) 143-150, http://dx.doi.org/10.1007/s10118-0141371-7.

[39] H.M.M. Tham, K.Y. Wang, D. Hua, S. Japip, T.S. Chung, From ultrafiltration to nanofiltration: hydrazine cross-linked polyacrylonitrile hollow fiber membranes for organic solvent nanofiltration, J. Membr. Sci. 542 (2017) 289-299, http://dx.doi. org/10.1016/j.memsci.2017.08.024.

[40] N. Peng, T.S. Chung, K.Y. Wang, Macrovoid evolution and critical factors to form macrovoid-free hollow fiber membranes, J. Membr. Sci. 318 (2008) 363-372, http://dx.doi.org/10.1016/j.memsci.2008.02.063.

[41] K. Hendrix, G. Koeckelberghs, I.F.J. Vankelecom, Study of phase inversion parameters for PEEK-based nanofiltration membranes, J. Membr. Sci. 452 (2014) 241-252, http://dx.doi.org/10.1016/j.memsci.2013.10.048.

[42] K. Hendrix, M. Van Eynde, G. Koeckelberghs, I.F.J. Vankelecom, Crosslinking of modified poly(ether ether ketone) membranes for use in solvent resistant nanofiltration, J. Membr. Sci. 447 (2013) 212-221, http://dx.doi.org/10.1016/j.memsci. 2013.07.002.

[43] S.C. Lu, A.L. Khan, I.F.J. Vankelecom, Polysulfone-ionic liquid based membranes for $\mathrm{CO}_{2} / \mathrm{N}_{2}$ separation with tunable porous surface features, J. Membr. Sci. 518 (2016) 10-20, http://dx.doi.org/10.1016/j.memsci.2016.06.031.

[44] M. Paul, S.D. Jons, Chemistry and fabrication of polymeric nanofiltration membranes: a review, Polymer (U.K.) 103 (2016) 417-456, http://dx.doi.org/10.1016/ j.polymer.2016.07.085.

[45] R. Verbeke, V. Gómez, I.F.J. Vankelecom, Chlorine-resistance of reverse osmosis (RO) polyamide membranes, Prog. Polym. Sci. 72 (2017) 1-15, http://dx.doi.org/ 10.1016/j.progpolymsci.2017.05.003.

[46] H.B. Park, B.D. Freeman, Z.B. Zhang, M. Sankir, J.E. McGrath, Highly chlorinetolerant polymers for desalination, Angew. Chem. - Int. Ed. 47 (2008) 6019-6024, http://dx.doi.org/10.1002/anie.200800454.

[47] D. Li, H. Wang, Recent developments in reverse osmosis desalination membranes, J. Mater. Chem. 20 (2010) 4551-4566, http://dx.doi.org/10.1039/B924553G. 